\title{
Effect of milk cessation method at dry-off on behavioral activity of dairy cows
}

\author{
P. J. Rajala-Schultz, ${ }^{\dagger} \dagger^{1}$ P. N. Gott, ${ }^{*}$ K. L. Proudfoot, ${ }^{*}$ and G. M. Schuenemann ${ }^{*}$ \\ *Department of Veterinary Preventive Medicine, The Ohio State University, Columbus 43210 \\ †Department of Production Animal Medicine, University of Helsinki, 04920 Saarentaus, Finland
}

\section{ABSTRACT}

Drying cows off at the end of lactation is a routine management practice in dairy operations. Most dairies in the United States and many other countries dry cows off abruptly (e.g., stop milking cows on a set day), which has been shown to affect cow comfort. Gradually reducing milk production is another approach to dry cows off, routinely used in some countries and herds. The objective of the study was to evaluate the effects of abrupt and gradual milk cessation and milk yield at the time on cow activity after dry-off. Daily lying time, number of lying bouts per day, average lying bout length, and steps taken per day by abruptly and gradually dried-off cows were monitored by data loggers for 2 wk before and after the final milking at the end of lactation. Gradual cows were milked once daily for the last week of lactation, and abrupt cows were milked as usual $(3 \times / d)$ until the end of lactation. Gradual cessation of milking significantly reduced milk yield by the day of dry-off. After dry-off, gradual cows tended to have longer lying bouts than abrupt cows, but no other differences in cow activity between the 2 treatments were observed. Regardless of the dry-off method, the average length of a lying bout decreased by $4 \mathrm{~min}$ and total daily lying time decreased by 19 min after dry-off for each 5 -kg increase in milk yield before dry-off. Lying behavior of primiparous cows was more affected by the level of milk yield at dry-off than that of older cows. A reduction in lying times with increasing milk yield may indicate discomfort due to the accumulating milk in the udder. Using a method that lowers milk production before dry-off and managing primiparous and multiparous cows separately around dry-off are beneficial for cow comfort after dry-off.

Key words: milk cessation method, abrupt, gradual dry-off, behavior

Received July 28, 2017.

Accepted December 18, 2017.

${ }^{1}$ Corresponding author: paivi.rajala-schultz@helsinki.fi

\section{INTRODUCTION}

The implementation of a 6- to 8-wk nonlactating (dry) period before a cow's next calving is a common practice in dairy herds to provide the cow's udder a period for cell regeneration between lactations. The effect of the dry period length on milk production and the importance of the dry period in general on health of a cow in the consecutive lactation have been intensely studied (Bachman and Schairer, 2003; Dingwell et al., 2003; Watters et al., 2008; Steeneveld et al., 2013). However, research on the methods used to dry cows off and their effect on udder health is surprisingly sparse. The first studies on the topic date back more than half a century and were conducted with cows producing significantly less milk than modern dairy cows (Wayne and Macy, 1933; Neave et al., 1950; Oliver et al., 1956). Abrupt and gradual cessation of milking were the methods studied, either with or without feed restriction. Abrupt cessation or "stop" milking occurs when normal daily milking is terminated on a set day, which is typically determined by the expected calving date and a desired dry period length. Gradual cessation of milking (also referred to as intermittent milking or reduced milking frequency) occurs when cows are weaned from milking over a period of days or weeks. This method of milk cessation is more aligned with what the cow would endure in nature, as her calf would gradually decrease milk intake before weaning (Vitale et al., 1986).

In addition to being more natural, gradually reducing milking frequency and the resulting lower milk yield at dry-off have been shown to be beneficial for udder health (Natzke et al., 1975; Oliver et al., 1990; Newman et al., 2010). In support of this idea, a more recent study reported that the involution process in cows producing low amounts of milk is associated with metabolic and immunological features that allow the cows to clear apoptotic cells and eliminate and prevent infections more effectively than cows dried off forcefully (abruptly) from large amounts of milk (Silanikove et al., 2013). However, with large herd sizes and intensification of the production, abrupt cessation of milking is the most commonly used drying-off procedure in many countries 
as it is easy and simple to implement (Barkema et al., 2015; Bertulat et al., 2015; USDA, 2016).

Recent research has found that abrupt milk cessation methods can also affect the affective state of the animals. For example, Bertulat et al. (2013) found that high-producing cows that were abruptly dried off had higher levels of fecal glucocorticoid metabolites, physiologic indicators of stress, compared with those that were gradually dried off. Zobel et al. (2013) reported that cows dried off abruptly showed strong motivation to be milked by standing at the gate leading to the milking parlor after dry-off, which the authors attributed to possible frustration with not being milked with the rest of the herd. It has also been suggested that an abrupt cessation of milking can cause discomfort as the udder becomes engorged with milk (O'Driscoll et al., 2011); however, evidence for this is lacking. For example, Zobel et al. (2013) measured lying time as an indirect measurement of discomfort in cows dried off abruptly and gradually, but found no difference in lying time between the treatments. Similarly, a study under New Zealand pasture conditions did not find any behavioral differences in lying bouts among groups of cows with different milking frequencies and feeding levels before and after dry-off (Tucker et al., 2009). Milk production levels in this pasture-based system, however, were lower than they typically would be when TMR and more energy-dense rations are fed. Another method to decrease milk production is to restrict the cow's feed intake; however, this method has been shown to cause increased vocalizations in cows, which has been interpreted as a behavioral sign of distress, potentially due to hunger (Valizaheh et al., 2008).

To our knowledge, no studies investigating the effect of different drying-off methods on dairy cow behavior have been conducted in US confinement systems or have specifically focused on the effect of high milk production at dry-off on lying behavior and activity of cows. Thus, the objectives of the current study were to evaluate the effects of (1) abrupt and gradual milk cessation and (2) milk yield on dairy cow lying behavior and activity around dry-off. It was hypothesized that higher milk yield before dry-off and abrupt cessation of milking, due to milk accumulation and consequent udder distension, would cause discomfort to the cow and this would be exhibited indirectly through changes in their activity and lying behavior.

\section{MATERIALS AND METHODS}

\section{Study Population}

This study was part of a larger project evaluating effects of 2 different milk cessation methods at dry-off on udder health, milk yield, and milk quality in the subsequent lactation, as described in Gott et al. (2016). All procedures used in the present study were approved by The Ohio State University Institutional Animal Care and Use Committee (protocol \#2011A00000136). The 2 drying-off methods assessed were abrupt and gradual cessation of milking. The sample size for the larger project was calculated based on expected differences in udder health parameters between the treatment groups (Gott et al., 2017). The study reported here was conducted in a single large Holstein herd, which was enrolled in the larger study. This herd had approximately 1,200 cows housed in freestall barns, and cows were milked 3 times a day, at 8-h intervals. Following the established on-farm protocol, cows were dried off abruptly once a week, and after the final milking, all quarters of all cows were treated with a commercially available antimicrobial dry cow product and internal teat sealants were also administered. No alterations were routinely made to the diet before dry-off in the herd, and the feeding management was not changed as a part of the study protocol either; thus, all cows remained on the farm's late lactation ration for the final week of lactation. After the final milking at the end of lactation, cows were moved to a dry cow pen with other dry cows.

During the larger project, cows with no observable clinical symptoms were enrolled 7 to $14 \mathrm{~d}$ before their dry-off date (PRE), which was based on cows' expected calving dates and the desired dry period length $(50 \mathrm{~d})$ in the herd. For this behavioral study, only cows that had activity data available for $14 \mathrm{~d}$ before and $14 \mathrm{~d}$ after dry-off were included in the activity data analyses. All cows to be dried off in $1 \mathrm{wk}$ were assigned to the same treatment [abrupt (ABR) or gradual (GRAD)] to make management of the cows easier for the herd personnel. Enrollment of cows occurred during spring and summer of 2014, and altogether, 4 sets of cows were enrolled during the spring (March-April) and 4 sets during the summer (July-August), and these sets varied in size between 7 to 24 cows. The first set of cows was assigned to the abrupt cessation group, and thereafter group assignment alternated weekly between gradual and abrupt cessation groups. Abrupt cessation cows maintained the farm's regular milking schedule $(3 \times / d)$ until the last day of lactation, whereas GRAD cows were milked once daily $(1 \times / d)$ for the final week of lactation. During the $1 \times$ milking period, GRAD cows were housed in the same pen and managed together with the rest of the late-lactation cows. All cows went through the parlor together during every milking, but GRAD cows were only milked once per day according to the study protocol. The GRAD cows were identified with brightly colored leg bands on one hind leg so the 
farm personnel knew to milk those cows only in the morning during the final week of lactation. After dryoff, all dry cows were housed in the same pen, fed the same ration, and otherwise managed the same way.

The herd had milk meters (AfiMilk USA Inc., Fitchburg, WI) in the milking parlor and milk yields for individual cows were recorded during each milking. Milk yield data for all study cows were obtained via the farm computer during the study period and imported to Microsoft Excel 2013 (Microsoft Corp., Redmond, WA). Milk yields from individual milkings were combined to represent daily milk yields at cow level $(\mathrm{kg} / \mathrm{d})$. The PRE milk yield used in the analyses was an average of cow-level milk yields from d 8 and 9 before dry-off. The milk yield on the last day of lactation was an average of cow-level milk yields from d 1 and 2 before dry-off.

\section{Activity and Lying Behavior}

At the time of enrollment (PRE; 7-14 d before dry off), an electronic data logger (IceQube, IceRobotics, Edinburgh, Scotland) was placed on a hind leg of a cow and kept on for $14 \mathrm{~d}$ after dry-off. The data loggers measured number of steps taken, lying time, and number of lying bouts. An average lying bout length was calculated by dividing the total lying time by the number of lying bouts. Lying times were expressed in hours per day and lying bout length in minutes per bout.

\section{Data Analyses}

The following criteria were used to include activity data from the study cows in the analyses: (1) data for a cow were available for $14 \mathrm{~d}$ before and $14 \mathrm{~d}$ after dry-off, and (2) she stayed in the herd through the dry period until her next calving. Data from days with full $24 \mathrm{~h}$ of recording were included; thus, data from the day of the placement of the activity monitors were omitted because only partial records were available for that day. Descriptive statistics on the activity parameters were calculated for each day of the study (d-14 to d14; d0 was defined as the day of dry-off). Descriptive statistics on the study cows were also calculated. Parity at dry-off (primiparous vs. multiparous), dry-off season (spring vs. summer), DIM at dry-off, and SCC on the last test day before dry-off (log-transformed for the analysis), and milk yield at enrollment and at dry-off were compared between the study groups (SAS Institute Inc., Cary, NC). Chi-squared test was used for comparing categorical variables and $t$-test for continuous variables between the study groups.

Activity data were analyzed using the MIXED procedure in SAS, v. 9.4 (SAS Institute Inc.). Daily summary measures of 4 different activity parameters (total lying time, number of lying bouts, average lying bout length, and number of steps taken) were used as the outcomes in separate analyses. Separate models for the data from before and after dry-off were run to assess the effect of the milk cessation method (ABR vs. GRAD) on the activity of cows. First, to ensure the groups were comparable, activity before the intervention ( $d-14$ to -8) was evaluated between the milk cessation groups. Second, to assess whether $1 \times$ milking affected activity of the GRAD cows during the intervention $(1 \times / d$ milking) week ( $\mathrm{d}-7$ to -1 ), their activity during that period was compared with their own activity during the preceding week $(\mathrm{d}-14$ to -8$)$. Pairwise differences between the baseline and the days of the intervention week were compared, adjusting for the multiple comparisons with Tukey's test. Third, the main interest was to compare activity of the GRAD and ABR cows after dry-off. In these analyses, data from 2 wk after dry-off (d 0 to 14) were considered and d 7 to 14 was used as the baseline level in the models. This time period was chosen as the baseline because it was expected that by then udder engorgement following dry-off would be already diminished, and any behavioral effects of regrouping cows would be minimal (Cook and Nordlund, 2004; Schirmann et al., 2011).

Milk cessation method (ABR vs. GRAD) was the main explanatory variable of interest. A variable distinguishing days with respect to the day of dry-off (DAYSDO) was created: the day of dry-off was designated as $\mathrm{d} 0$ and days before dry-off were marked with negative values ( $\mathrm{d}-14$ to -1 ) and days after dry-off with positive values (d 1 to 14). The DAYSDO, cow's parity (categorized as primiparous and multiparous at dry-off), DIM at dry-off, logSCC on last test day, milk yield at enrollment (PRMI) and at dry-off (DRMI), and season of dry-off were first tested in univariable models for an association with the activity parameters. Variables associated with the activity measures with $P$ $<0.2$ were included in a full model and dropped one at a time until all remaining variables were considered significant using $P<0.05$. Milk cessation method, however, was tested in all models as the main variable of interest. The PRMI and DRMI were not included in the same model due to high correlation. Also, because milk cessation method significantly affected DRMI, these 2 variables were not included in the models simultaneously, as DRMI was deemed as an intervening variable. Different covariance structures [variance components, $\operatorname{AR}(1), \operatorname{ARH}(1)$, compound symmetry, unstructured] were tested and compound symmetry fitted the data best, based on Akaike's information criterion. Consequently, it was used in all models to account for the correlated data structure between the daily observa- 
tions from individual cows. The DAYSDO was used as the repeated measure in the models. A variable was also created to indicate the 8 weekly sets of cows dried off on the same day, and this was used in the models as a random effect. Two-way interactions between milk cessation method and other variables in the final models were tested. Fit of the models was checked using diagnostic residual plots.

\section{RESULTS}

\section{Descriptive Data}

Altogether, 95 cows, 48 ABR and 47 GRAD cows, were enrolled in the study. Data from 58 cows, 29 ABR and 29 GRAD cows, met the inclusion criteria and were available for the activity analyses. Eleven cows were excluded from the study because they were, by mistake, milked $1 \times / \mathrm{d}$ for $2 \mathrm{wk}$, and 2 cows (both ABR) were excluded because they had been diagnosed with a clinical disease within a week before enrollment and they were still recovering from it during the study as later judged from their daily milk yield records. Other reasons for exclusion were as follows: cows lost the activity monitor during the study or it was on only for a week before dry-off $(\mathrm{n}=11)$, cows had clinical mastitis at dry-off ( $\mathrm{n}=5 ; 3$ GRAD, 2 ABR cows), cows aborted or were diagnosed open during the dry period $(\mathrm{n}=4)$, and cows were culled or they died during the dry period (n $=4,2$ for foot problems, one for gastrointestinal problems, one for an unknown reason). Descriptive statistics on the study cows are presented in Table 1. Somatic cell count (log-transformed) on the last test day, DIM at dry-off, and parity distribution did not differ between the milk cessation groups. Over half of the cows in both groups were first-lactation cows, entering their first dry period. Fewer GRAD cows were included in summer because one summer group of $1 \times$ cows was by mistake milked $1 \times$ for 2 wk and therefore those cows were excluded. At enrollment, daily milk yield did not differ between the groups $(23.9 \pm 1.3 \mathrm{~kg}$, range 10.7 to 39.1 for GRAD vs. $24.7 \pm 1.6 \mathrm{~kg}$, range 9.9 to 46.2 for ABR), but at dry-off the GRAD cows produced significantly less milk than the ABR cows $(14.3 \pm 1.0$ $\mathrm{kg}$; range 5.8 to $24.4 \mathrm{~kg}$ vs. $22.7 \pm 1.6 \mathrm{~kg}$; range 8.3 to $46.2 \mathrm{~kg}$, respectively, Table 1).

\section{Activity and Lying Behavior Before Dry-Off}

Summaries of daily activity of the cows (total daily lying time, average lying bout length, number of lying bouts, and steps taken) before dry-off are presented in Figure 1. Considerable individual variation from cow to cow and day to day was observed, but on average cows laid down $10.7 \pm 2.5 \mathrm{~h} / \mathrm{d}$ (mean $\pm \mathrm{SD}$ ) during the 2-wk period before dry-off. The average length of a lying bout during this time was $73( \pm 30) \mathrm{min} /$ bout; cows had on average $9.8( \pm 3.5)$ lying bouts/d and took $2,497( \pm 515)$ steps daily. The GRAD and ABR cows did not differ in their activity during the week before the intervention (Figure 1). Additionally, lying behavior or the number of daily steps of the GRAD cows did not significantly change during the intervention [i.e., the last week of lactation ( $d-7$ to -1$)$, when compared with the baseline ( $d-14$ to -8 before dry-off); results from the models not shown, Figure 1)].

\section{Activity and Lying Behavior After Dry-Off}

Univariable Screening. In the univariable screening, milk cessation method was not significantly $(P>$ 0.05) associated with any of the outcomes, but milk yield before dry-off (both PRMI and DRMI) was associated with lying bout length, total lying time, and number of steps taken. The number of daily lying bouts was not associated with milk cessation method nor milk yield before dry-off. The DAYSDO was significantly associated with all activity measures, with the numerically largest and significant differences observed during the first 2 to $3 \mathrm{~d}$ after dry-off when compared with the baseline period. LogSCC was not associated with any of the outcomes.

Lying Bout Length. Of the lying behaviors measured, the average length of a lying bout appeared to be most affected by the dry-off method. Results from the final model with the average lying bout length as the outcome are presented in Table 2. Gradually dried-off cows tended to have approximately 9 min longer lying bouts than abruptly dried-off cows after dry-off. The DAYSDO was associated with lying bout length, with cows having significantly shorter lying bouts on the day of dry-off and the $2 \mathrm{~d}$ following dry-off than during the second week of the dry period. Each 5 -kg increase in PRMI shortened the length of an average lying bout by about 4 min. If DRMI was included instead of PRMI and milk cessation method dropped from the model, a similar effect was seen: higher milk yield significantly decreased the length of a lying bout (by $5 \mathrm{~min}, P=$ 0.0011). Older cows had shorter lying bouts after dryoff compared with primiparous cows, and cows dried off during spring had longer lying bouts than cows dried off in summer.

Our earlier results from this project indicated that primiparous and multiparous cows responded differently to the 2 milk cessation methods with respect to their udder health (Gott et al., 2016, 2017) and we hypothesized that their behavioral activity may differ as well. Therefore, lying bout length of primiparous and 
Table 1. Descriptive data on gradually and abruptly dried-off Holstein cows enrolled in a study assessing the effect of milk cessation method and milk yield on dairy cow activity around dry-off ${ }^{1}$

\begin{tabular}{|c|c|c|c|}
\hline Item & Abrupt $(\mathrm{n}=29)$ & Gradual $(\mathrm{n}=29)$ & $P$-value \\
\hline \multicolumn{4}{|l|}{ Parity $^{3}$ (no., \%) } \\
\hline 1 & $18(62.1)$ & $17(58.6)$ & \multirow[t]{2}{*}{0.7884} \\
\hline $2+$ & $11(37.9)$ & $12(41.4)$ & \\
\hline $\mathrm{PRMI}^{4}(\mathrm{~kg})$ & $24.7 \pm 1.6$ & $23.9 \pm 1.3$ & 0.7176 \\
\hline $\mathrm{DRMI}^{4}(\mathrm{~kg})$ & $22.7 \pm 1.6$ & $14.3 \pm 1.0$ & 0.0001 \\
\hline $\operatorname{logSCC}$ at last test day ${ }^{4}$ & $4.9 \pm 1.2$ & $4.6 \pm 1.4$ & 0.4748 \\
\hline DIM at dry ${ }^{4}$ & $364 \pm 12$ & $335 \pm 8$ & 0.0557 \\
\hline \multicolumn{4}{|l|}{ Dry-off season ${ }^{3}$ (no., \%) } \\
\hline Spring & $11(37.9)$ & $18(62.1)$ & \multirow[t]{2}{*}{0.0660} \\
\hline Summer & $18(62.1)$ & $11(37.9)$ & \\
\hline
\end{tabular}

${ }^{1}$ Gradual cessation cows were milked once daily for the final week of lactation and then dried off. Abrupt cessation cows followed the farm's normal milk schedule $(3 \times / \mathrm{d})$ until dry-off.

${ }^{2} P$-values reflect comparisons between the study groups, using chi-squared test for categorical and $t$-test for continuous variables.

${ }^{3}$ The percentages indicate the proportions within treatment groups.

${ }^{4}$ The mean \pm SE are reported. PRMI is an average of $\mathrm{d} 8$ and 9 before dry-off, and DRMI is an average of $\mathrm{d}$ 1 and 2 before dry-off.

multiparous cows after dry-off was examined in more detail by running separate models for the 2 groups of cows: milk cessation method was not significant in either model $(P>0.4$ and thus dropped) and DRMI was included in the model instead of PRMI, as it was considered to better reflect the situation at the time
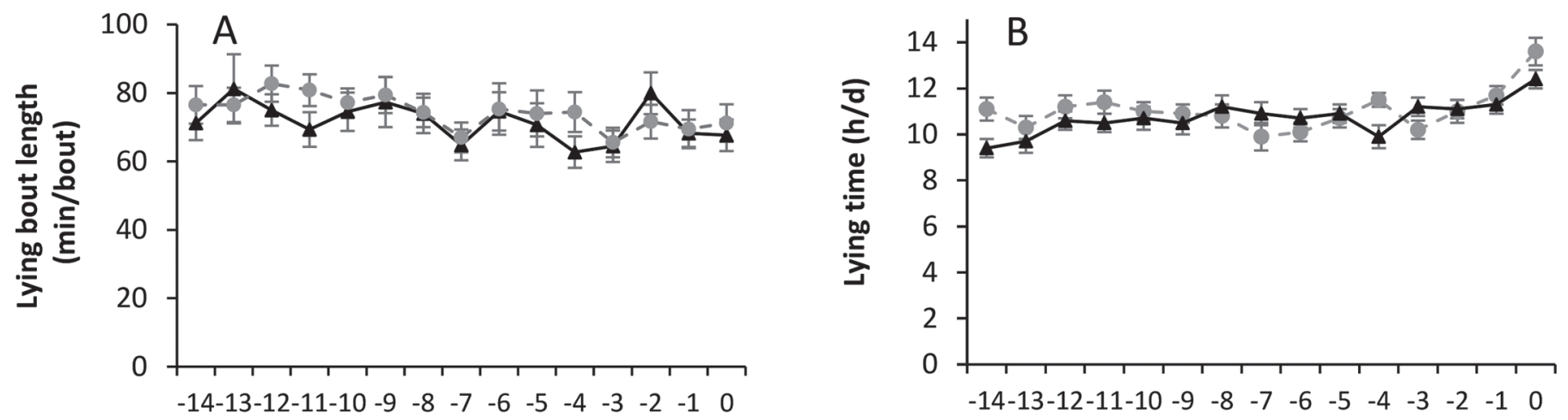

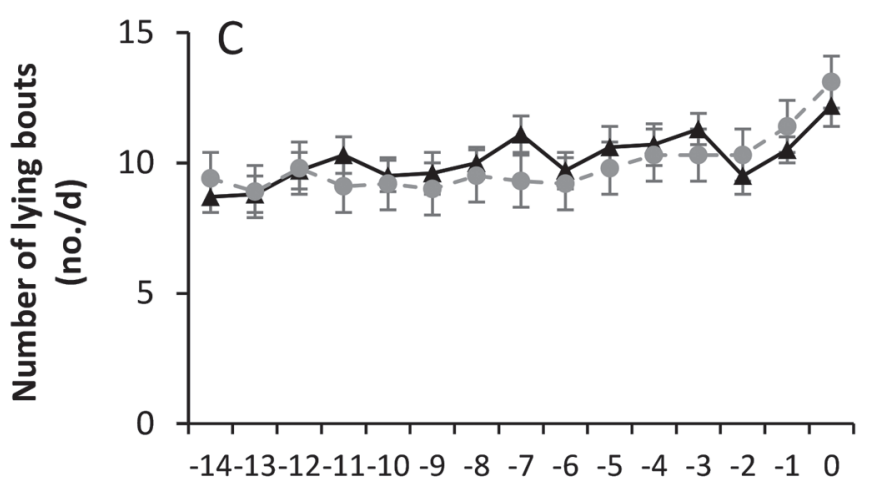

Days before dry-off

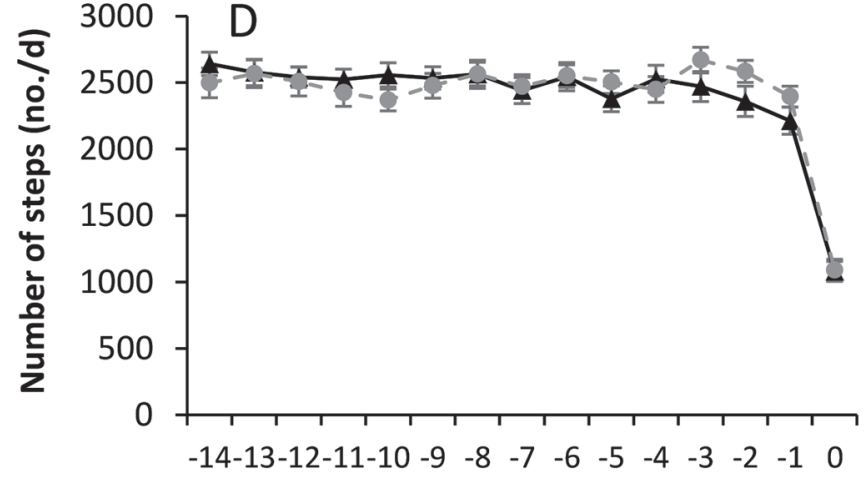

Days before dry-off

Figure 1. Summary data on daily activity and lying behavior measures (mean \pm SE) among abruptly (dark solid line with triangles, $\mathrm{n}=$ 29 ) and gradually (gray dashed line with circles, $\mathrm{n}=29$ ) dried off cows during the last 2 wk before dry-off. Data include lying bout length (A), lying time (B), the number of lying bouts (C), and the number of steps (D). On d -7 the intervention started and gradual cows were only milked once daily, even though they went through the parlor at all 3 milkings. Abrupt cows remained on $3 \times$ milking/d until the day of dry-off ( $\mathrm{d} 0$ ). 
of dry-off. Cows going through their first dry period appeared to be more affected by high milk yield at dryoff than older cows (Table 3). As DRMI increased by $5 \mathrm{~kg}$, the average lying bout length was shortened by 6 min among primiparous cows, whereas among the older cows the effect only tended toward significance and was numerically smaller.

Daily Lying Time. Total daily lying time after dryoff was not significantly associated with milk cessation method (Table 2). However, similarly to lying bout length, higher PRMI significantly reduced daily lying time, by $0.31 \mathrm{~h} / \mathrm{d}(19 \mathrm{~min} / \mathrm{d})$ for each 5 - $\mathrm{kg}$ increase. The total daily lying time of primiparous and multiparous cows did not differ, but DAYSDO, season of dryoff, and DIM at dry-off were associated with daily lying time. An interaction between milk cessation method and DAYSDO was significant $(P=0.0007)$ and separate models were run for the study groups, with DRMI in the model. In the ABR group, daily lying time was significantly shorter on d 2, 3, and 4 after dry-off (up to 1.1 h shorter on d 2, $P=0.0008)$ compared with baseline (2nd week of the dry period, d 7 to 14), and with every 5 -kg increase in DRMI daily lying time decreased by $0.4 \mathrm{~h}$ (or $25 \mathrm{~min}, P=0.0353$ ). In the GRAD group, on the other hand, DRMI was not associated with lying time $(P=0.2553)$ and no differences in lying time were observed across days after dry-off $(P>0.6)$, except that cows laid down $1.3 \mathrm{~h}$ longer $(P<0.0001)$ on the day of dry-off compared with baseline.

Number of Lying Bouts and Steps. The number of lying bouts or steps taken after dry-off were not affected by the milk cessation method $(P>0.8$ and $P>$ 0.4 , respectively) nor by milk yield at dry-off, but DAYSDO was significantly associated with both of these parameters $(P<0.001)$. Cows had significantly more lying bouts on the day of dry-off and during the first 2 d after dry-off compared with the baseline (results from the final models not shown). A clear and significant decrease was observed in the number of steps taken after dry-off when compared with the time before dryoff (Figure 1). Cows also took fewer steps on the day of dry-off and during the first week of the dry period when compared with the second week after dry-off.

The tested 2-way interactions, such as those between milk cessation method and DAYSDO, parity, season, or milk yield at enrollment, were not significant in any of the models, except for interaction between milk cessation method and DAYSDO for the total daily lying

Table 2. Results from the final models ${ }^{1}$ assessing the effect of milk cessation method and milk yield before dry-off on cow lying behavior, with lying bout length and daily lying time after dry-off as the outcomes ${ }^{2}$

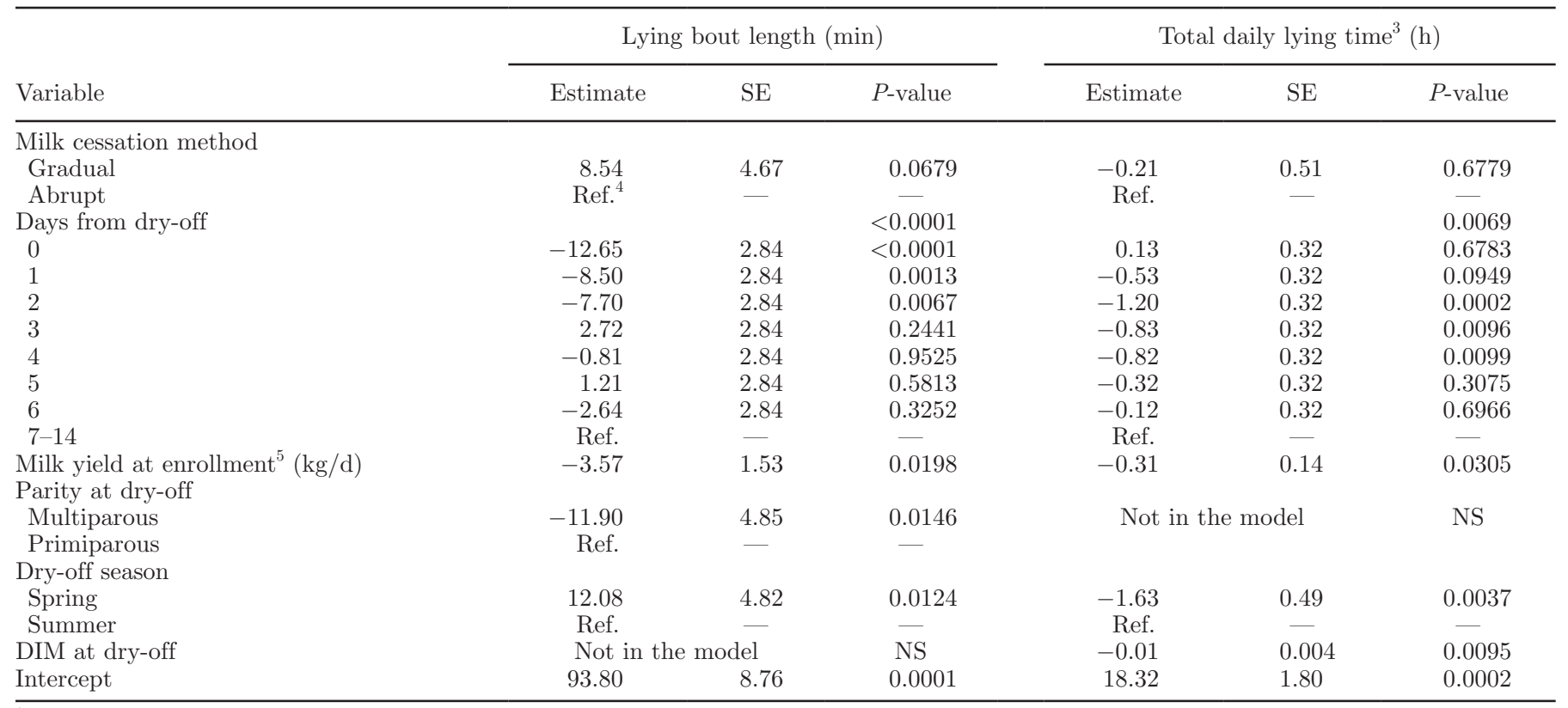

${ }^{1}$ Gradual cessation cows were milked once daily for the final week of lactation and then dried off. Abrupt cessation cows followed the farm's normal milk schedule $(3 \times / d)$ until dry-off.

${ }^{2}$ Correlated data structure between daily observations from individual cows was accounted for using compound symmetry covariance structure, and "dryset" (a weekly set of cows dried off together) was included as a random effect in the model.

${ }^{3}$ Interaction term between milk cessation method and days from dry-off was significant in the daily lying time model, but is not shown in the table.

${ }^{4}$ Ref. $=$ reference level to which other levels of the categorical variable were compared.

${ }^{5}$ An average milk yield from d 8 and 9 before dry-off, scaled to reflect a 5-kg change. 
Table 3. Results from the final model, ${ }^{1}$ stratified by parity, assessing the effect of milk yield on lying bout length after dry-off in a Holstein herd housed in a free-stall barn

\begin{tabular}{|c|c|c|c|c|c|c|}
\hline \multirow[b]{2}{*}{ Variable } & \multicolumn{3}{|c|}{ Primiparous $(\mathrm{n}=35)$} & \multicolumn{3}{|c|}{ Multiparous $(\mathrm{n}=23)$} \\
\hline & Estimate & $\mathrm{SE}$ & $P$-value & Estimate & $\mathrm{SE}$ & $P$-value \\
\hline Days from dry-off & & & 0.0065 & & & 0.0131 \\
\hline 0 & -12.00 & 3.92 & 0.0023 & -13.64 & 3.98 & 0.0007 \\
\hline 1 & -8.25 & 3.92 & 0.0359 & -8.87 & 3.98 & 0.0265 \\
\hline 2 & -9.49 & 3.92 & 0.0159 & -4.97 & 3.98 & 0.2128 \\
\hline 5 & 2.31 & 3.92 & 0.5670 & -0.35 & 3.98 & 0.9304 \\
\hline 6 & -1.32 & 3.92 & 0.7369 & -4.65 & 3.98 & 0.2431 \\
\hline $7-14$ & Ref. $^{3}$ & - & - & Ref. & - & - \\
\hline \multicolumn{7}{|l|}{ Dry-off season } \\
\hline Spring & 14.21 & 7.74 & 0.0670 & 8.78 & 7.70 & 0.2556 \\
\hline Summer & Ref. & - & - & Ref. & - & - \\
\hline Intercept & 103.71 & 9.96 & $<0.0001$ & 81.91 & 7.16 & $<0.0001$ \\
\hline
\end{tabular}

${ }^{1}$ Correlated data structure between daily lying bout lengths of a cow was accounted for using compound symmetry covariance structure and by including "dryset" (a weekly set of cows dried off together) as a random effect in the model.

${ }^{2} \mathrm{An}$ average milk yield from d 1 and 2 before the day of dry-off, scaled to reflect a 5 -kg change.

${ }^{3}$ Ref. $=$ reference level to which other levels of the categorical variable were compared.

time. Assessment of the diagnostic residual plots did not reveal any violations regarding normality of the residuals or raise any other concerns about the fit of the models. Least squares means and standard errors from the final models for the 4 activity parameters among $\mathrm{ABR}$ and GRAD cows after dry-off are presented in Figure 2.

\section{DISCUSSION}

The main objective of the study was to assess the effect of gradual and abrupt cessation of milking and milk yield at dry-off on activity of dairy cows after the final milking at the end of the lactation. Results from this study indicated that cows' lying behavior, as described by average lying bout length and total daily lying time, was affected by dry-off, especially within the first 2 to $3 \mathrm{~d}$ after the cessation of milking. Cows dried off gradually tended to have longer lying bouts than abruptly dried-off cows during the first week after dry-off. Furthermore, milk cessation method significantly affected the level of milk production at dry-off, which in turn was associated with the lying behavior. Although no differences were present in milk yield at the beginning of the study between the study groups, gradual dry-off significantly reduced milk production, in agreement with previous reports (Davis et al., 1999; Tucker et al., 2009; Newman et al., 2010).

A main finding from this study was that cows producing high amounts of milk at dry-off had shorter lying bouts and shorter daily lying time after dry-off than their lower-producing herdmates. This may indi- cate pain or discomfort associated with the cessation of milking, as modern high-producing dairy cows often produce substantial amounts of milk at the time of dryoff (Chapinal et al., 2014; Gott et al., 2017) and lying down on the distended, engorged udder can be painful. Drying cows off abruptly based on expected calving date is a widely implemented management practice in many countries (Dingwell et al., 2001; Bertulat et al., 2015; USDA, 2016). Because milk synthesis continues several days after the final milking, the accumulating milk can cause considerable increase in the internal pressure and distension of the mammary gland, especially among high-producing cows (Davis et al., 1999). In dairy cows, udder engorgement has been reported to be highest on d 2 after dry-off (Bertulat et al., 2013; Bach et al., 2015). Fecal glucocorticoid metabolites, indirect stress indicators, increased in all cows after sudden dry-off, peaked at the same time when the udder pressure was greatest and this was most pronounced among the highest producing cows (Bertulat et al., 2013). Udder engorgement or pressure was not measured in the current study, but the most significant changes observed in the lying behavior coincided with the timing of reported peak udder engorgement. This could imply cows were experiencing discomfort, as suggested by others (Tucker et al., 2007; Bertulat et al., 2013; Chapinal et al., 2014). The terms pain and discomfort are often used interchangeably in the literature related to drying-off of dairy cows. Both terms refer to something unpleasant, subjectively experienced by the animal; however, pain has a definition as "an unpleasant sensory and emotional experience associated with 
actual or potential tissue damage, or described in terms of such damage pain" (IASP, 2017). During the involution process, mammary secretory tissue goes through apoptotic, programmed cell death (Capuco and Akers, 1999; Silanikove et al., 2013) and the term pain appears appropriate in this context.

We had anticipated that $1 \times$ milking could cause some pain due to filling of the udder and this would be seen in more frequent and shorter lying bouts and more steps taken by the cows on the gradual dry-off treatment during the intervention week compared with their own activity before the intervention. However, no such effects were observed, in agreement with the results of Tucker et al. (2009), who did not find behavioral differences around dry-off in pasture conditions. It is worthwhile, though, to keep in mind the differences in milk production levels of cows raised on pasture and in confinement. Stefanowska et al. (2000), on the other hand, reported that especially high-producing cows in mid lactation with omitted milking showed some signs of discomfort based on longer standing times in the cubicles and more frequent urination after the omitted milkings. Otherwise, once a day milking in mid and late lactation has been reported to have only minor effects on the behavior of milking cows and not to impair welfare of cows (Pomiès et al., 2007; Tucker et al., 2007; O'Driscoll et al., 2011). Also based on the results of the current study, it appears that reduced milking frequency at the end of lactation does not affect lying behavior before dry-off, but it could improve cow comfort after dry-off by reducing the level of milk production before the final milking. Additionally, we previously reported that reduced milking frequency before dry-off was associated with lower SCS in the subsequent lactation (Gott et al., 2017). Gradual dryoff and lower milk yield at the time of dry-off have also been associated with less milk leakage after dry-off and fewer IMI at the following calving (Oliver et al., 1990; Rajala-Schultz et al., 2005; Zobel et al., 2013), even though parity differences may exist (Gott et al.,
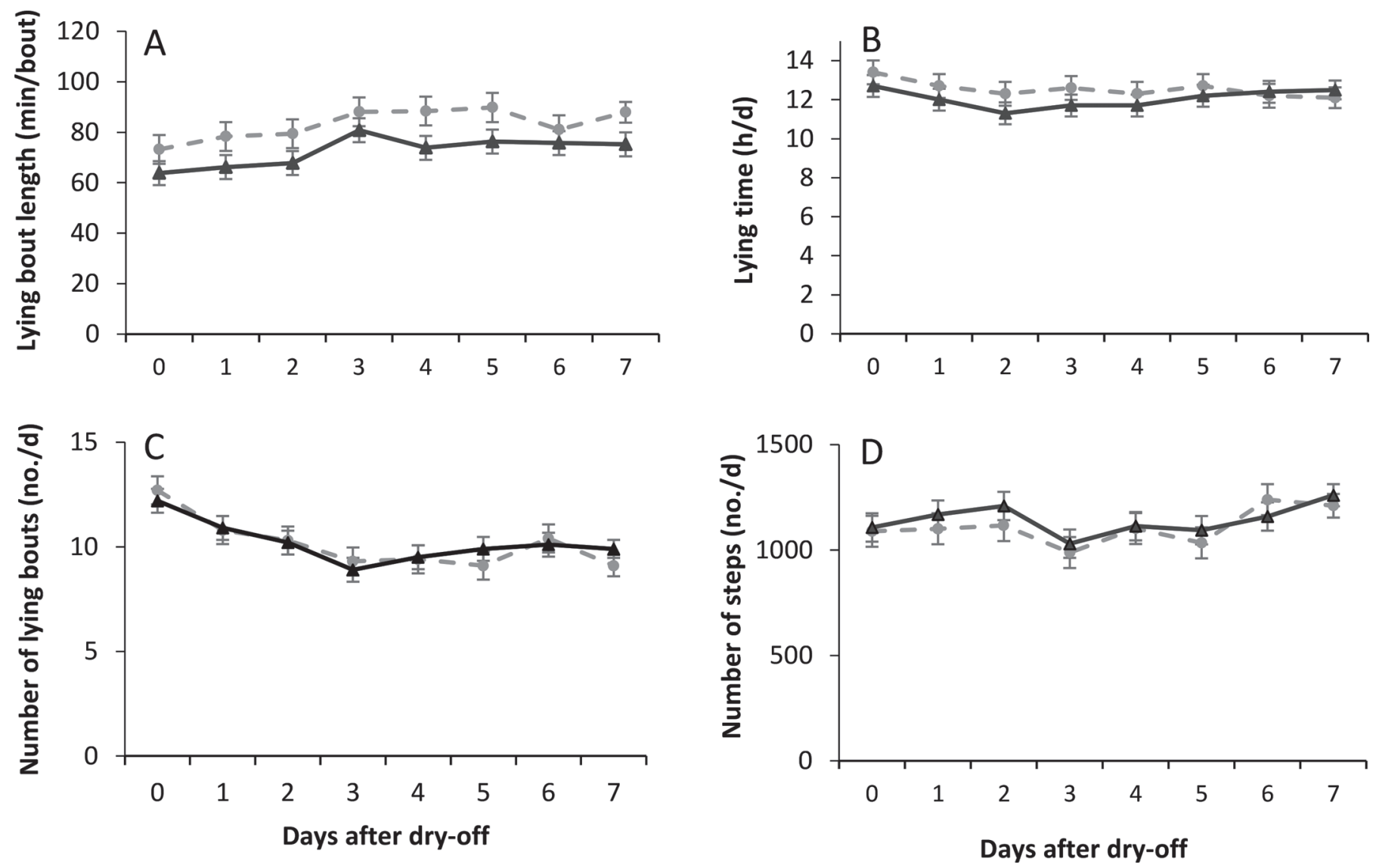

Figure 2. Least squares means ( $\pm \mathrm{SE}$ ) of average lying bout length $(\mathrm{A})$, lying time $(\mathrm{B})$, the number of lying bouts $(\mathrm{C})$, and the number of steps (D) after dry-off from respective final mixed effects models among abruptly (dark solid line with triangles, $\mathrm{n}=29$ ) and gradually (gray dashed line with circles, $\mathrm{n}=29$ ) dried off cows during the first week of the dry period (d 0 was the day of dry-off). Gradual cows were milked once daily for the last week of lactation, even though they went through the parlor at all 3 milkings. Abrupt cows remained on $3 \times$ milking/d until the day of dry-off (d 0). 
2016). Even though the current, widely implemented practice of abrupt dry-off is justified by easy execution and reduced labor demands in the increasingly larger dairy herds compared with gradual dry-off, both udder health and cow comfort perspectives warrant reconsideration of this practice.

Cows dried off using a gradual method in the current study could not be sorted or separated into their own group during the period of reduced milking frequency. Instead they entered the milking parlor with the rest of the late lactation group at every milking, but were only milked once a day. This was an initial concern due to the potential milk letdown and leakage of milk as this could keep teat ends open and predispose cows to IMI. However, the herd personnel did not report any concerns about milk leakage during the $1 \times$ period and we did not notice this affecting udder health of the GRAD cows during the intervention week in the larger study (Gott et al., 2016, 2017). This arrangement, however, provided us an excellent opportunity to compare the activity of the cows between the milk cessation groups as well as among the cows in the gradual dry-off treatment during different time periods: the analyses were not confounded by the time away from the pen and walking to and standing in the holding pen and in the parlor across $1 \times$ and $3 \times$ milking/d. Different number of milkings/d undoubtedly affects time budget and activity of the cows and this was clearly seen in the current study as well. The number of steps dropped dramatically starting on the day of dry-off in both groups when the cows were not walking to the parlor any more.

The results of the current study showed that milk cessation method and milk yield at dry-off have a different effect on the behavior of primiparous and multiparous cows. Higher milk yield at the end of lactation had a significant and more noticeable effect on the lying bout length of primiparous cows when compared with that of older cows. This is in agreement with results of Chapinal et al. (2014) who speculated that multiparous cows may not experience udder discomfort due to distension to the extent younger cows do or that they may be familiar with the sensation. Also, a recent study compared behavior of primi- and multiparous transition cows and due to the differences observed in feeding and lying behavior, the authors concluded that primiparous cows may benefit from different management during the transition period (Neave et al., 2017).

The idea about different management for different age groups is corroborated also by the current as well as our earlier results (Gott et al., 2016) which indicated that milk cessation methods had a different effect on udder health among primi- and multiparous cows: gradual cessation of milking among primiparous cows was associated with reduced risk of IMI, whereas the opposite was true for multiparous cows. Additionally, changes in management, such as regrouping of animals, disrupt the social structure of a group and increase agonistic interactions for 2 to $3 \mathrm{~d}$ (von Keyserlingk et al., 2008; Schirmann et al., 2011) and low-ranking animals, such as primiparous cows, are most affected by these management changes and likely to experience stress (Gonzalez et al., 2003; Cook and Nordlund, 2004). Because the dry period lays the foundation for the next lactation, it is crucial to avoid all unnecessary stressors that could impair cows' defense mechanisms and predispose them to infections or other ailments, such as metabolic disorders during the transition period. Gradually drying off cows may help improve cow health and comfort by reducing milk yield prior the final milking and making laying down more comfortable for high producing dairy cows.

\section{CONCLUSIONS}

High milk yield before dry-off shortened the lying bout length and daily lying time of cows regardless of treatment. If cows were dried off gradually, which significantly reduced their milk yield before the final milking, they tended to have longer lying bouts compared with cows dried off abruptly. Lying time of primiparous cows was more affected by milk production level before dry-off compared with multiparous cows, suggesting that different drying off practices for primiparous and multiparous cows may be beneficial. These results add to the growing evidence that using a gradual method for milk cessation at the end of lactation is beneficial for dairy cows, as it lowers milk production before the final milking and allows for better cow comfort at dryoff.

\section{ACKNOWLEDGMENTS}

The investigators thank the participating dairy producer and on-farm personnel for providing the animals and their valuable collaboration during the present study. This project was supported by Agriculture and Food Research Initiative Competitive Grant no. 201267015-30203 from the USDA National Institute of Food and Agriculture, Washington, DC.

\section{REFERENCES}

Bach, A., A. De-Prado, and A. Aris. 2015. Short communication: The effects of cabergoline administration at dry-off of lactating cows on udder engorgement, milk leakages, and lying behavior. J. Dairy Sci. 98:7097-7101.

Bachman, K. C., and M. L. Schairer. 2003. Invited review: Bovine studies on optimal lengths of dry periods. J. Dairy Sci. 86:30273037 . 
Barkema, H. W., M. A. von Keyserlingk, J. P. Kastelic, T. J. Lam, C. Luby, J. P. Roy, S. J. LeBlanc, G. P. Keefe, and D. F. Kelton. 2015. Invited review: Changes in the dairy industry affecting dairy cattle health and welfare. J. Dairy Sci. 98:7426-7445.

Bertulat, S., C. Fischer-Tenhagen, and W. Heuwieser. 2015. A survey of drying-off practices on commercial dairy farms in northern Germany and a comparison to science-based recommendations. Vet. Rec. Open 2:e000068.

Bertulat, S., C. Fischer-Tenhagen, V. Suthar, E. Mostl, N. Isaka, and W. Heuwieser. 2013. Measurement of fecal glucocorticoid metabolites and evaluation of udder characteristics to estimate stress after sudden dry-off in dairy cows with different milk yields. J. Dairy Sci. 96:3774-3787.

Capuco, A. V., and R. M. Akers. 1999. Mammary involution in dairy animals. J. Mammary Gland Biol. Neoplasia 4:137-144.

Chapinal, N., G. Zobel, K. Painter, and K. E. Leslie. 2014. Changes in lying behavior after abrupt cessation of milking and regrouping at dry-off in freestall-housed cows: A case study. J. Vet. Behav. 9:364-369.

Cook, N. B., and K. V. Nordlund. 2004. Behavioral needs of the transition cow and considerations for special needs facility design. Vet. Clin. North Am. Food Anim. Pract. 20:495-520.

Davis, S. R., V. C. Farr, and K. Stelwagen. 1999. Regulation of yield loss and milk composition during once-daily milking: A review. Livest. Prod. Sci. 59:77-94.

Dingwell, R. T., D. F. Kelton, and K. E. Leslie. 2003. Management of the dry cow in control of peripartum disease and mastitis. Vet. Clin. North Am. Food Anim. Pract. 19:235-265.

Dingwell, R. T., D. F. Kelton, K. E. Leslie, and V. L. Edge. 2001. Deciding to dry-off: Does level of production matter? Pages 69-79 in Proc. Annual Meeting of National Mastitis Council. NMC, Reno, NV.

Gonzalez, M., A. K. Yabuta, and F. Galindo. 2003. Behaviour and adrenal activity of first parturition and multiparous cows under a competitive situation. Appl. Anim. Behav. Sci. 83:259-266.

Gott, P. N., P. J. Rajala-Schultz, G. M. Schuenemann, K. L. Proudfoot, and J. S. Hogan. 2016. Intramammary infections and milk leakage following gradual or abrupt cessation of milking. J. Dairy Sci. 99:4005-4017.

Gott, P. N., P. J. Rajala-Schultz, G. M. Schuenemann, K. L. Proudfoot, and J. S. Hogan. 2017. Effect of gradual or abrupt cessation of milking at dry off on milk yield and somatic cell score in the subsequent lactation. J. Dairy Sci. 100:2080-2089.

IASP (International Association for the Study of Pain). 2017. IASP Taxonomy, Pain Terms. International Association for the Study of Pain. Accessed Nov. 26, 2017. https://www.iasp-pain.org/ Taxonomy.

Natzke, R. P., R. W. Everett, and D. R. Bray. 1975. Effect of drying off practices on mastitis infection. J. Dairy Sci. 58:1828-1835.

Neave, F. K., F. H. Dodd, and E. Henrichs. 1950. Udder infections in the dry period. J. Dairy Res. 17:37.

Neave, H. W., J. Lomb, M. A. von Keyserlingk, A. Behnam-Shabahang, and D. M. Weary. 2017. Parity differences in the behavior of transition dairy cows. J. Dairy Sci. 100:548-561.

Newman, K. A., P. J. Rajala-Schultz, F. J. Degraves, and J. Lakritz. 2010. Association between milk yield and infection status at dryoff and intramammary infections at subsequent calving. J. Dairy Res. 77:99-106.

O'Driscoll, K., D. Gleeson, B. O'Brien, and L. Boyle. 2011. Does omission of a regular milking event affect cow comfort? Livest. Sci. $138: 132-143$.
Oliver, J., F. H. Dodd, and F. K. Neave. 1956. Udder infections in the dry period. III. The method of drying-off cows in the dry period. J. Dairy Res. 23:197-203.

Oliver, S. P., E. P. Shull, and H. H. Dowlen. 1990. Influence of different methods of milk cessation on intramammary infections during the periparturient period. Pages 92-97 in Proc. International Symposium on Bovine Mastitis. National Mastitis Council, American Association of Bovine Practitioners, Indianapolis, IN.

Pomiès, D., B. Martin, Y. Chilliard, P. Pradel, and B. Remond. 2007. Once-a-day milking of Holstein and Montbeliarde cows for 7 weeks in mid-lactation. Animal 1:1497-1505.

Rajala-Schultz, P. J., J. S. Hogan, and K. L. Smith. 2005. Association between milk yield at dry-off and probability of intramammary infections at calving. J. Dairy Sci. 88:577-579.

Schirmann, K., N. Chapinal, D. M. Weary, W. Heuwieser, and M. A. von Keyserlingk. 2011. Short-term effects of regrouping on behavior of prepartum dairy cows. J. Dairy Sci. 94:2312-2319.

Silanikove, N., U. Merin, F. Shapiro, and G. Leitner. 2013. Early mammary gland metabolic and immune responses during natural-like and forceful drying-off in high-yielding dairy cows. J. Dairy Sci. 96:6400-6411.

Steeneveld, W., Y. H. Schukken, A. T. van Knegsel, and H. Hogeveen 2013. Effect of different dry period lengths on milk production and somatic cell count in subsequent lactations in commercial Dutch dairy herds. J. Dairy Sci. 96:2988-3001.

Stefanowska, J., M. Plavsic, A. H. Ipema, and M. M. Hendriks. 2000. The effect of omitted milking on the behaviour of cows in the context of cluster attachment failure during automatic milking. Appl. Anim. Behav. Sci. 67:277-291.

Tucker, C. B., D. E. Dalley, J. L. Burke, and D. A. Clark. 2007. Milking cows once daily influences behavior and udder firmness at peak and mid lactation. J. Dairy Sci. 90:1692-1703.

Tucker, C. B., S. J. Lacy-Hulbert, and J. R. Webster. 2009. Effect of milking frequency and feeding level before and after dry off on dairy cattle behavior and udder characteristics. J. Dairy Sci. 92:3194-3203

USDA. 2016. Dairy 2014 Milk Quality, Milking Procedures, and Mastitis on U.S. Dairies, 2014. USDA-APHIS-VS-CEAH-NAHMS, Fort Collins, CO.

Valizaheh, R., D. M. Veira, and M. A. G. von Keyserlingk. 2008. Behavioural responses by dairy cows provided two hays of contrasting quality at dry-off. Appl. Anim. Behav. 109:190-200.

Vitale, A., M. Tenucci, M. Papini, and S. Lovari. 1986. Social behaviour of the calves of semi-wild Maremma cattle, Bos primigenius taurus. Appl. Anim. Behav. Sci. 16:217-231.

von Keyserlingk, M. A. G., D. Olenick, and D. M. Weary. 2008. Acute behavioral effects of regrouping dairy cows. J. Dairy Sci. 91:10111016.

Watters, R. D., J. N. Guenther, A. E. Brickner, R. R. Rastani, P. M. Crump, P. W. Clark, and R. R. Grummer. 2008. Effects of dry period length on milk production and health of dairy cattle. J. Dairy Sci. 91:2595-2603.

Wayne, R., and H. Macy. 1933. The effect of various methods for drying up cows on the bacterial and cell content of milk. J. Dairy Sci. 16:79-91.

Zobel, G., K. Leslie, D. M. Weary, and M. A. von Keyserlingk. 2013. Gradual cessation of milking reduces milk leakage and motivation to be milked in dairy cows at dry-off. J. Dairy Sci. 96:5064-5071. 